The Journal of the American Osteopathic Association September/1981

Spinal segmental dysfunction:

Incidence in cervicothoracic region

Vincristine toxicity

What characterizes an osteopathic principle?

Selected responses to an open question

Brainstem-evoked responses

CME quiz, page 13
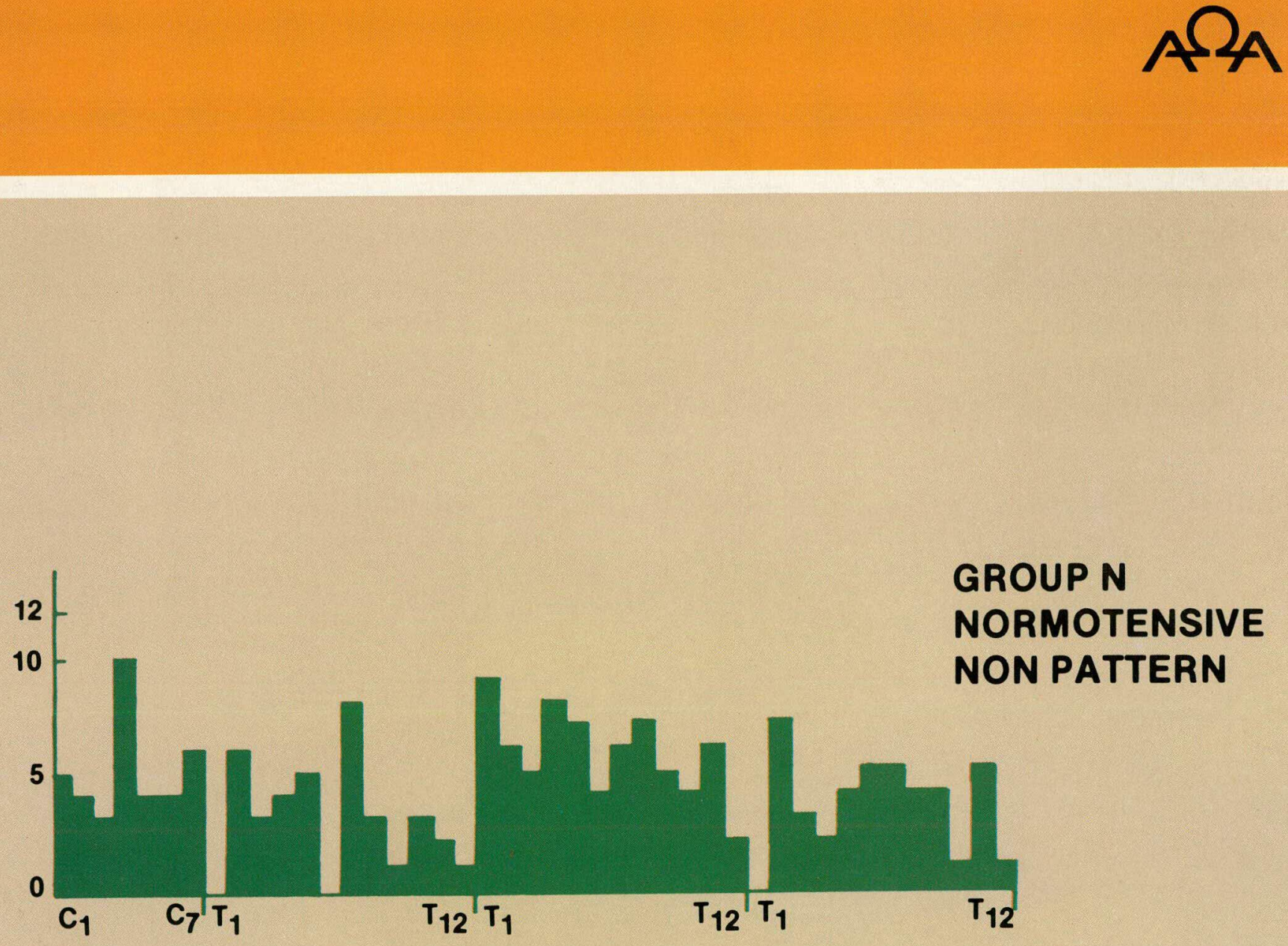


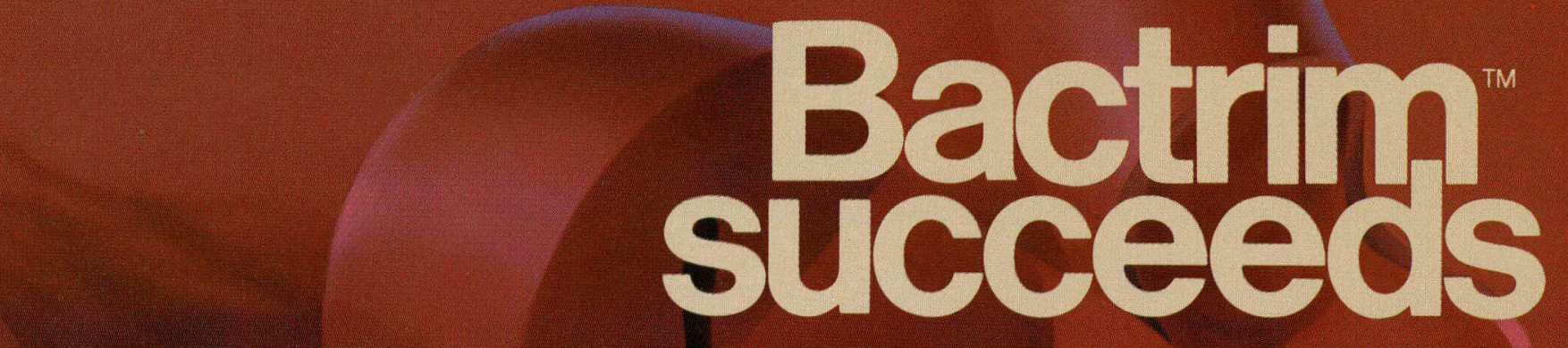

\section{in recurrent urinary tract infections}

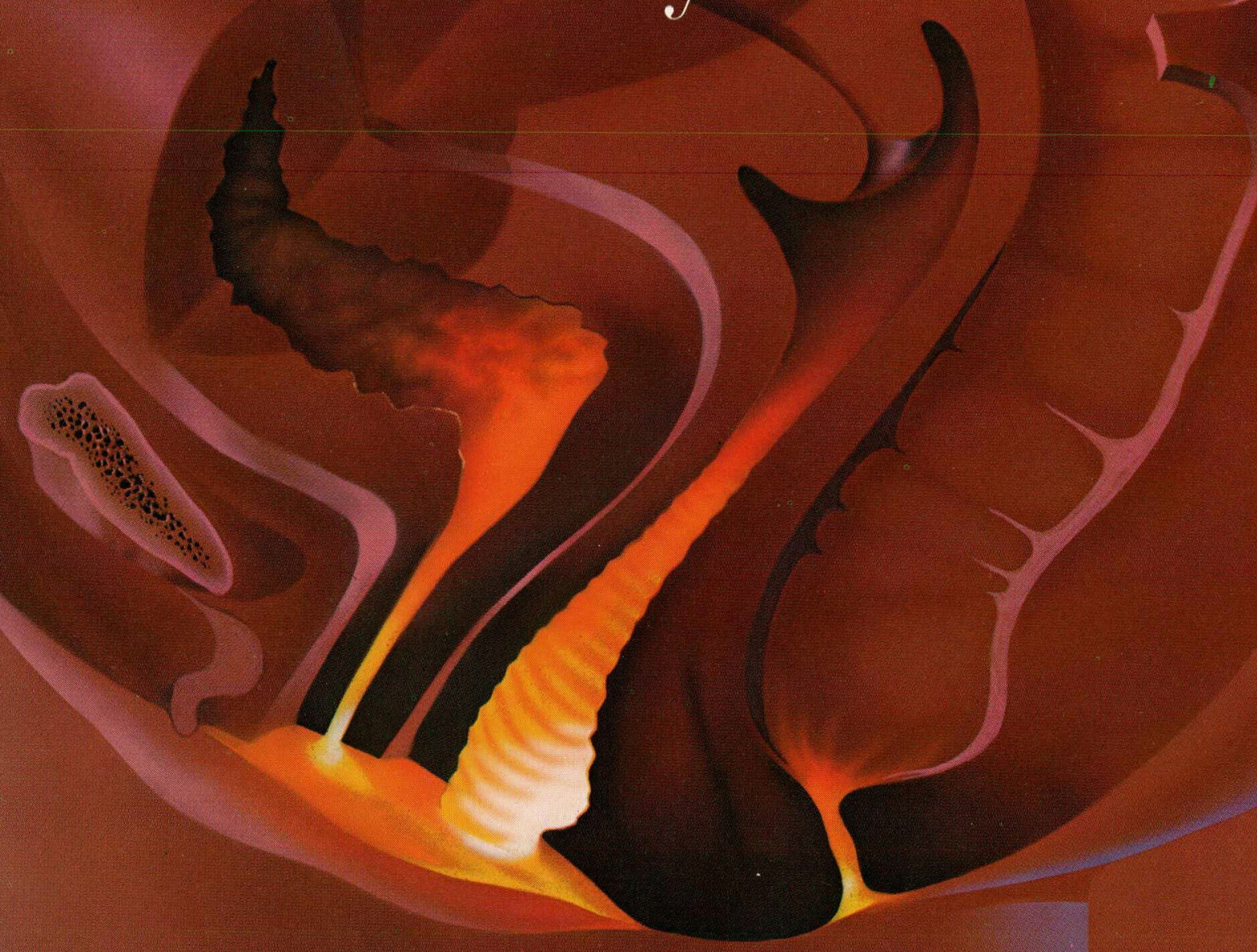

\section{from site tosource}

Bactrim reaches effective levels in urine, serum and renal tissue, ${ }^{1}$ to combat infection throughout the urinary tract. The trimethoprim component enters vaginal secretions in therapeutic concentrations, ${ }^{1}$ to prevent colonization of bacteria in the periurethral area, probably the major etiologic factor in recurrent UTI., ${ }^{2,3}$ And in the fecal flora, Bactrim eradicates Enterobacteriaceae with no resulting emergence of resistant organisms and without adverse effect on the normal intestinal flora. 